\title{
Tracing a Black Hole: Probing Cosmic Darkness in Anthropocenic Times
}

\author{
Jessie Beier
}

\section{SeEINg the UnSeEAble}

On April 10, 2019, the team at the Event Horizon Telescope (EHT) project released an unprecedented image of a supermassive black hole at the centre of galaxy Messier 87. The image, which shows a dark disc outlined by swirling hot gas circling the black hole's event horizon, exhibits a 55-million-year-old cosmic event in the Virgo galaxy cluster-a void of stellar mass measuring some 6.5 billion times that of Earth's sun. After almost a decade of work and the collaboration of an international team of scientists, a network of radio telescopes synched through atomic clocks and the creation of a powerful algorithm capable of correlating and calibrating huge amounts of data while sifting through "noise," the image produced by the EHT has been offered as unprecedented "visual evidence" of what has, until now, been invisibleevidence of the event horizon of a black hole (Drake, 2019). As EHT director and astrophysicist Shep Doelman put it when introducing the image, "[w]e are delighted to be able to report to you today that we have seen what we thought was unseeable. We have seen and taken a picture of a black hole" (cited in Chappell, 2019) (Fig. 3.1).

While the news of this extraordinary image was but a blip on newsfeeds at the time, its significance has reverberated throughout scientific communities, where the picture has been hailed as a "precious" techno-scientific discovery

J. Beier $(\varangle)$

University of Alberta, Edmonton, AB, Canada

e-mail: jlbeier@ualberta.ca 


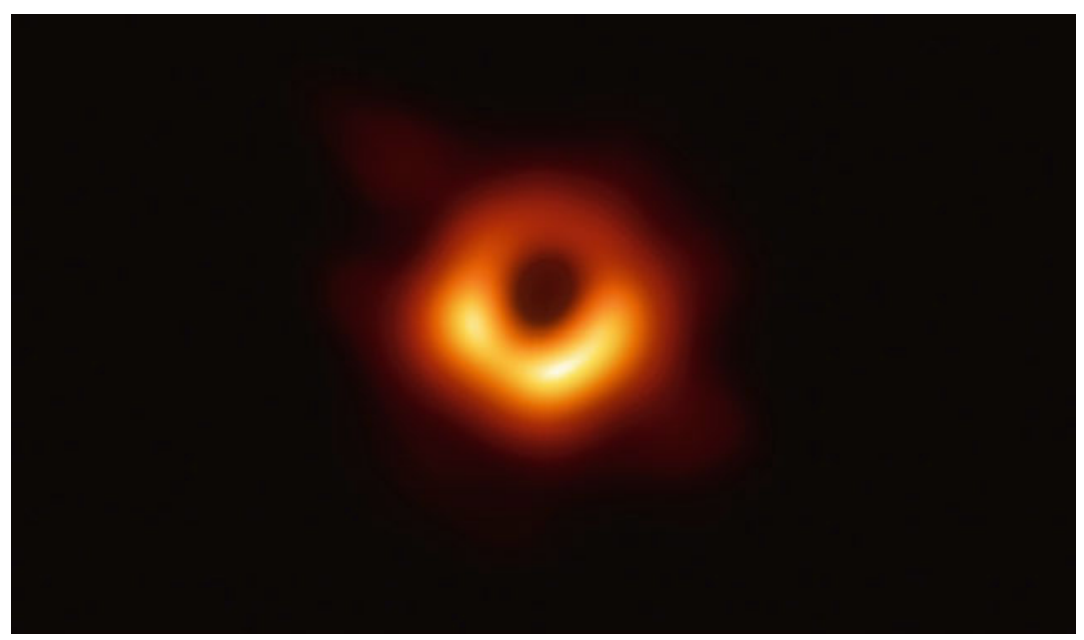

Fig. 3.1 Radio image of the black hole located in Messier 87, EHT Collaboration (2019)

that affirms some of the most important theories subtending the field of astrophysics (Chappell, 2019). For instance, Einstein's theory of general relativity and its related calculations were used to predict the size and shape of the black hole's event horizon, which was then confirmed with the image, resulting in a renewed confidence in the physics that is said to drive the large-scale structure of the universe (Chappell, 2019). While there have been extensive simulations created in order to speculate on how the laws of physics might extend to the outer limits of deep space, black holes have never been directly observed, and thus have not, until this image, been empirically "proven." With this in mind, the 2019 image has been deemed precious because, as Heino Falcke, chair of the EHT Science Council put it, "this one is finally real" (my italics, cited in Chappell, 2019).

The image has also been deemed significant based on the technical ingenuity required to visually represent such a distant and compact cosmic event. In order to reach into the depths of spacetime, the globally dispersed EHT team needed to create an extremely large and powerful telescope, one at least 10,000 kilometres in diameter or almost as big as planet Earth. Due to the material impossibility of such an endeavour, the team responded by developing the EHT, a computational telescope, which, combined with a powerful algorithm, is capable of resolving structure on the scale of a black hole's event horizon.

Beyond affirming fundamental scientific theories and demonstrating what is possible through well-funded and technologically innovative international scientific collaboration, the image has also been celebrated for the cosmological presumptions it seemingly affirms, that is, presumptions about humanity and our role and place in the cosmos. For instance, upon its release, the image 
was dubbed a beacon of hope, a "ray of light" in these dark times (O'Hagan, 2019). As Guardian journalist Ellie May O'Hagan (2019) put it on the day of the image's publication:

On our own turquoise speck in the cosmos, we're living through ecological breakdown, the rise of authoritarianism and the appallingly unequal distribution of resources. We're devoting a lot of time and energy to destroying our home and to hurting one another. It can be hard not to feel like the human race has become trapped in its own event horizon, and we're inevitably and inexorably being pulled towards the darkness. The grainy image those scientists released on Wednesday reminds us of something different.

Counter to the melanoheliophobic narratives that often circle around discussions of black holes (for instance, at the press conference where the image was introduced the black hole was described as "[t]he gates of hell, the end of space and time,") O'Hagan highlights a more optimistic narrative, one wherein this scientific and technological feat is a testament to the ingenuity, curiosity, and resourcefulness of the human species. In this narration, the black hole image is not only celebrated for its techno-scientific implications, but, importantly for this investigation, also for the optimistic narratives of human progress and futurity it seemingly affirms.

In what follows, I continue to trace the image produced by EHT in terms of such narratives, but also in terms of the counter-narratives that might be speculatively deployed when questions of human progress and futurity are put in contact with the strange logic of black holes and their imaging. This tracing is situated within what has been labelled (contentiously, as we will see) the Anthropocene, a geologic era wherein the magnitude, variety, and longevity of human-induced transformations have emerged as a geological force now altering the planet's climate and environment (Lewis \& Maslin, 2015). More specifically, this tracing is situated within the milieu of (science) education today and takes off from the increasingly common, if uncomfortable, claim that contemporary educational domains are ill-conceived and ill-equipped to deal with the urgent, if illusive, concept of the Anthropocene and thus what is required is a "substantial rethinking [of education] —of its content, its purposes and its relationships" (Gilbert, 2016, p. 188).

With this call for "substantial rethinking" in mind, this tracing brings the black hole image in contact with the site of (science) education today in order to experiment with how questions of sustainability and, ultimately, educational futurity might be resituated given the planetary shifts on the horizon (or that are, in many cases, already here). Through a series of brief forays into black hole physics, historical examples of cosmic imaging and further exploration of the image created by EHT, this tracing outlines the black hole and its apparent horizons in order to propose a strange vantage point from which pedagogical problem-posing might be interrupted, mutated, and relaunched. 
By turning to that which lies outside of the traditional science classroombeyond the school, beyond curriculum, beyond state-imposed policy, national rankings and international benchmarks, indeed, beyond the planet itself, deep into the cosmos - this tracing seeks to probe this black hole event in terms of its weird and weirding pedagogical trajectories so as to speculate on unthought possibilities for resituating (science) education in the age of the Anthropocene.

\section{Apparent Horizons: Cosmological Shifts, Pedagogical Resituation}

A black hole is typically described as what remains after a star is unable to resist gravity and collapses inwards. This process, sometimes called the "death" of a star, is more accurately the result of what happens when high-mass stars use up their fuel at a pace that creates a supernova explosion, resulting in an altered gravitational state. As a more common naming of what had been previously called Totally Gravitationally Collapsed Objects, the name "black hole" references both light and gravity: black holes are considered "black" because they are a place in space where gravity pulls so much that light cannot get out, and they are considered "holes" because the dense inner region of a black hole, known as its singularity, permanently warps spacetime, thus creating a "hole" in the fabric of the universe. As such, a black hole does not have a surface, but is instead defined by a special boundary called an event horizon. The pedagogical example often used to simulate this strange cosmic boundary is the one where an astronaut shines a flashlight on either side of the black hole's event horizon. If the flashlight is outside of the event horizon, then the light rays are able to escape the pull of gravity and thus can be seen from a distance. If the flashlight is at or inside of the event horizon, however, the light cannot escape the gravitational pull produced by the collapsed star, and thus any light emitted is trapped inside of the black hole. It is this threshold between (human) visibility and invisibility that defines the event horizon of a black hole.

Of course, it is not exactly the case that the light is "trapped," but rather that it is unobservable from the vantage of the astronaut. This realization shines light on, so to speak, one of the most interesting, if vexing, scientific debates surrounding black holes and their cosmological implications. That is, physicists remain largely undecided as to whether the prediction of black holes and their singularities, supported as they are by fundamental theories about the "laws" and structure of the universe, actually exist (or existed at some point), or if it is the case that current knowledge and theories of the cosmos are simply insufficient to describe what happens at such extremely dense points in spacetime. As such, the very concept of the event horizon-that special boundary beyond which events cannot affect a human observer-is still up for debate, catalyzing difficult questions about, for instance, the nature of photon spheres, black hole thermodynamics, Hawking radiation, and information-loss paradoxes, to name but a few research trajectories. 
Stephen Hawking (2014), for instance, suggested that the very idea of an event horizon should be replaced with what he called "apparent horizons," an assertion founded on the claim that quantum effects around a black hole cause spacetime to fluctuate too wildly for a sharp boundary surface to exist. In contrast to an event horizon, which refers almost exclusively to the possibility of an absolute horizon, that is, one defined teleologically in terms of an asymptotically flat spacetime, an apparent horizon is instead dependent on the "slicing" of spacetime. Put another way, unlike an event horizon, which relies on an absolute horizon-one that is very geometrical and requires the full history (all the way into the future) of spacetime in order to be known-the very location and even existence of an apparent horizon instead depends on the way that spacetime is itself divided into space and time. Put yet another way, which is sometimes necessary when grappling with astrophysical concepts (at least for me), apparent horizons are not invariant and immutable properties of spacetime that can be known in advance, but are instead local and observer-dependent - the boundary at this instant-whereas an event horizon is the boundary of a black hole for light in the future, where the future is defined teleologically by the laws of physics.

What is important to note here is not how this distinction works to deny the existence of black holes and their singularities, but rather, how the definitions and narrative contingencies of scientific phenomena are interpolated within a set of broader cosmological presumptions. This is not to say that there are no particular facts or regularities between certain certainties, that everything can be reduced to social constructions and cultural tropes, but rather, that the "laws" and definitions that chase these regularities are always contingent. In the case of black holes, for example, the very definition of a black hole varies radically, often in conflicting ways, based on the disciplinary background and cosmological milieus from which such definitions emerge (Curiel, 2019 , p. 27). As Erik Curiel (2019) suggests, this uncertainty around black hole definitions is not so much about the lack of a single, canonical answer but rather that "there are too many good possible answers to the question, not all consistent with each other" (p. 27). For Curiel, then, the multitude of definitions is an important virtue of research related to black holes, not something to be resolved or unified. What matters, then, is how such definitions are purposefully interpolated into scientific practice across domains and for different theoretical, observational, and foundational contexts (Curiel, 2019, pp. 33-34).

In her essay Platform Cosmologies: Enabling Resituation, artist, writer, and designer Patricia Reed (2019) provides a provisional framework for understanding such interpolations, honing in on the relationship between techno-scientific development and cosmological shifts. In this essay, Reed works to think through the conditions for enabling resituation given today's planetary realities by asking how techno-scientific change manifests, how it is narrated, how it is oriented by purposes, and, ultimately, how such purposes might be reoriented towards a desired otherworld (p. 27). Drawing on the 
work of political scientist Bentley Allan, Reed highlights how "despite the import of scientific development as a catalyst for novel understandings of the world, it's not until these developments become interpolated into a cosmological order that they begin to influence general purposefulness within it" (p. 28). In this way, Reed draws attention to the role and import of the narrative contextualization of techno-scientific developments and how such narrations work to operationalize new knowledge, both socially and politically, in turn impacting broader cosmological presumptions. For Reed, this focus on narrative contingency marks an important difference between merely acquiring new knowledge about the world and existing in that knowledge, which, she notes, "entails working out how one navigates the world anew with this knowledge, as well as its instrumentalization" (p. 28).

In the case of a black hole and its unprecedented imaging, then, Reed might say that the importance of such a discovery lies not only in what it can tell us about ourselves and our place in the universe, but also in how such narrations are purposefully extended into particular domains so as to affirm (or negate) cosmological presumptions. In this way, the question of enabling resituation, that is, enabling the interpolation of new knowledge and cosmological shifts adequate to the pressing challenges on the horizon today, is not just about knowing more or even knowing differently, but instead, the "cosmological stakes lie in making claims on the construction of social, political, and ethical narrations to ramify the meanings we ought to extrapolate from them, influencing a cosmological milieu we need for their just deployment" (p. 29). Returning back to the specific cosmological milieu of this investigation, to the site of (science) education in/and the Anthropocene, I draw upon Reed's platform for enabling resituation in order to experiment with what it might mean for educational thought to exist in an encounter with a black hole. It is through this encounter that I aim to grapple with the difficult question of pedagogical resituation today.

While calls for rethinking, re-orienting, re-imagining, etc.... (science) education are becoming more and more pronounced against the backdrop of transformed and transforming planetary realities, responding adequately to such calls remains incredibly difficult. This is not only due to the immense effort, energy, and time required, but because such thinking is itself limited by what it cannot think, or as educational theorist Jane Gilbert (2016) notes, "the conceptual categories that structure our thinking are themselves part of the problem" (p. 188). For Gilbert (2016), this means any sort of educational re-imagining must confront its own assumptions and limits: "we need to look at ourselves to dig up some of our assumptions about science education-what it is and what it is for-and [thus] our assumptions about science, education, society and the future" (p. 190). Such a confrontation not only involves grappling with the difficult task of interrogating cosmological presumptions and their pedagogical ramifications, but importantly, I wager, this confrontation must experiment with putting educational thought in contact with what it is currently unable to think - in contact with the (apparent) horizons of thinking 
itself-so as to put pressure on the conceptual categories that delimit thinking in the first place.

As Reed notes, it is through the transformative activity of thinking itself, of constructing concepts in relation to objects, that we might be resituated (p. 30). That is, through the mutual formation between thought and its (apparent) object, "the situatedness of all thought (located within a particular cosmological milieu) always contains the possibility of overflowing its situation" (Reed, 2019, p. 30). It is through this spillage that alien milieus and yet unthought pedagogical trajectories open up. In what follows, I endeavour towards such encounters and experimentation by bringing the black hole image produced by EHT in contact with this question of pedagogical resituation, and specifically, with some of the conceptual categories and narrative contingencies that undergird the (Good) Anthropocene and its visions for a sustainable education.

\section{Messages to Humanity: From Earthrise to Pōwehi}

Upon its release, the image produced by the Event Horizon Telescope team was quickly placed into the lineage of those other iconic environmental photographs - for example, Earthrise (1968), The Blue Marble (1972), The Pale Blue Dot (1990) — that have "both captured the public imagination and offered scientists insight into how the universe works" (Reuell, 2019). As EHT science council member Dan Marrone noted at the time of the image's release, "photos can change the way we think about ourselves and our place in the universe." To support this claim, Marrone likened the black hole image to Earthrise, a photo taken by Apollo 8 astronaut Bill Anders in December of 1968 (Fig. 3.2).

Earthrise is often cited as both an inspirational and aspirational image, widely credited for helping to spur the environmental movement and for influencing scientific and ecological theories, such as Lovelock and Margulis' Gaia Hypothesis. ${ }^{1}$ Captured during the first manned mission to the moon, Earthrise shows a small and delicate Earth rising over a rugged grey lunar surface, "a magnificent spot of colour in the vast blackness of space" (Anders, 2018). Upon encountering the wondrous view during lunar orbit, part of which was broadcasted live into homes across America on December 24, 1968, Apollo 8's mission astronauts expressed feelings of humility, gratitude, and admiration as they described the unprecedented sight. Command Module Pilot Jim Lovell, for instance, stated that "the vast loneliness is awe-inspiring and it makes you realize just what you have back there on Earth" (cited in Williams, n.d.) In short, and as adventure photographer Galen Rowell has asserted, Earthrise is

\footnotetext{
${ }^{1}$ The Gaia Hypothesis proposes that the Earth and its organisms form a synergistic complex system that self-regulates so as to maintain and propagate the conditions for life. By providing a view of this complex system as a whole from the vantage of space, Earthrise has been attributed to influencing this hypothesis.
} 


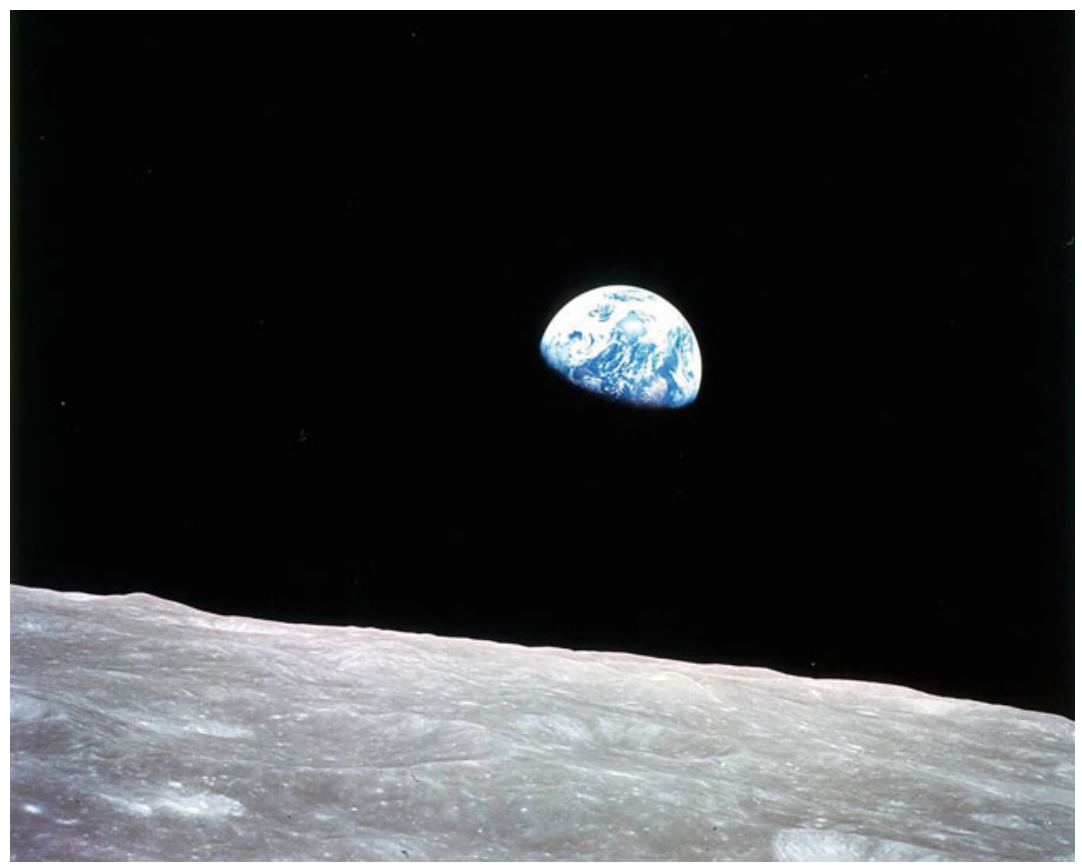

Fig. 3.2 Earthrise, NASA (1968)

considered "the most influential environmental photograph ever taken" due to the way in which it has inspired contemplation about our fragile existence and our place in the cosmos (cited in Coulter, 2009). Since its release, Earthrise has not only continued to rank high on lists of era-defining images, but has also become a common representational stand-in for environmental protection and planetary stewardship. Showing up on NASA-endorsed stamps and influential magazines such as Life and Time, as well as in countercultural texts ranging from Stewart Brand's Whole Earth Catalogue to Joni Mitchell's 1976 song "Refuge of the Roads," this view of Earth from a distance has been called a "message for humanity," a message of both our cosmic insignificance and the precious nature of this planet we call Home.

It is to this lineage that Marrone was perhaps referring, one wherein the black hole image not only provides evidence of an unprecedented encounter with the mysteries of the cosmos, but, more importantly, acts as a catalyst for bringing about broader social, cultural, and cosmological shifts. Fast forward just over 50 years, however, and it is clear that while Earthrise has become a common trope within environmental communications, the notion that this image has been an impetus for more care-full planetary stewardship is today dubitable, particularly given the increasingly disastrous state of the planet. As crises converge and proliferate across the globe-i.e., uncontrollable fires and historic flooding but also unprecedented droughts, the end of farmable 
land, food scarcity, climate plagues and global pandemics, unbreathable air, poisoned oceans, the list goes on and on and on-it appears that Earthrise's "message to humanity" has gone all but unanswered.

Resituated within the cosmological milieu of the Anthropocene, Earthrise no longer tells a story of cosmic humility and planetary protection, but instead spins a tale of anthropic omnipotence, one narrated from a God-like perspective, a "view from nowhere" as Donna Haraway (1988) might have it, that unifies vision across time and space from but a single (all-too-human) perspective. Returning to the Apollo 8 Christmas Eve broadcast, it is perhaps interesting to note that after sharing pictures of the Earth and Moon as seen from lunar orbit, the live broadcast (the most watched TV programme at the time) ended with the crew taking turns reading from the book of Genesis (Williams, n.d.). Refracted through this God-like view, with its fantasies of both dominion and salvation, the Earth in Earthrise is transformed from a precious "blue dot" in need of protection to a mutable object over which "we" can exert control and domination, extracting and exploiting for anthropocentric ends. Not unlike the image itself, which was edited so as to exaggerate the Earth's presence (NASA flipped the photo and cropped it in order to make the Earth a bigger focal point ${ }^{2}$ ), from the vantage of the Anthropocene, Earthrise's "message to humanity" is manipulated to satisfy anthropocentric ends. From this vantage, Earthrise no longer reads as a symbol of environmental stewardship, but instead, as a stand-in for assumptions about human control, manipulation, and ultimately, mastery over planetary life.

With this in mind, the case may be made that the black hole image follows in the lineage of Earthrise based on how it too tells a story of human mastery, cosmic frontierism, and an understanding of progress defined by "the recursively institutionalized, neoclassical economic ideal that 'human progress [is equal to] the unleashing of scientific and technological progress itself" (Reed, 2019 , p. 29). Indeed, this narration was characteristic of the mainstream dispatches that circulated upon the image's release. As O'Hagan (2019) wrote in her optimistic report, "[a]s far as we know, we are alone in the infinite darkness-yet we have not succumbed to despair of this terrible possibility. Instead, we have looked out into the darkness, transfixed by its mystery. The universe is spellbinding and miraculous, but so are human beings" (my italics). Like Earthrise before it, the narrative contingencies emanating from the black hole image tell a story of an ingenious human species, one that is discrete and separate from the cosmos, but nevertheless able to image its deep mysteries. It is this characterization of humanity, situated as it is within a broader set of cosmological presumptions, through which the Anthropocene itself is often narrated, particularly in its "Good" iterations.

The idea of the "Good Anthropocene" originated with Erle Ellis, a landscape ecologist and senior fellow at The Breakthrough Institute, who champions what he calls "postnatural environmentalism" and the assertion

\footnotetext{
2 see Moran (2018).
} 
that we should "forget Mother Nature" and recognize that "this is a world of our making" (Ellis, 2009, 2011). According to Ellis, if we first "stop trying to save the planet," then we can embrace the Anthropocene and our new role in it as "the creators, engineers, and permanent global stewards of a sustainable human nature" (my italics, Ellis, 2011). In many ways, Ellis' “Good Anthropocene" is perhaps just a more explicit articulation of how the Anthropocene has been narrated more generally, that is, as the expansion and extension of yet another epic story where humanity-anthropos - is not only capable of transforming planetary realities, but more importantly, "if 'we' discover ourselves to be an agent of destruction, then 'we' must re-form, re-group and live on" (Cohen \& Colebrook, 2016, p. 9).

Whereas the introduction of the Anthropocene might otherwise be positioned as a conceptual "shock," "a point of bifurcation in the history of the Earth, life and humans [that] overturns our representations of the world" (Bonneuil \& Fressoz, 2016, p. 29), a "Good Anthropocene" is "one in which humans can be proud of their achievements rather than lose too much sleep over the side effects" (Ellis cited in Zylinska, 2018, pp. 16-17). As Joanna Zylinksa (2018) writes in her proposal for a feminist counter-apocalypse, the Anthropocene not only signals our presently unfolding planetary emergency, but also offers a "new epistemological filter through which we humans can see ourselves" (p. 3). Zylinska discusses how dominant Anthropocene narratives fail to recognize how their own discursive tropes and points of reference "bring forth a temporarily wounded yet ultimately redeemed man who can conquer time and space by rising above the geological mess he has created!" (my italics, Zylinksa, 2018, p. 12). Evidenced through, for instance, the immortality projects of Silicon Valley and the interstellar colonization projects of Elon Musk's SpaceX, the Anthropocene ushers in narratives wherein something like anthropogenic climate change merely requires a "technical fix," and thus, anthropos himself is also "fully fixable" through projects aimed at human upgrade and redemption (p. 18). As Zylinska highlights, in the tale of the (Good) Anthropocene the human is reinstalled as the protagonist, the ultimate hero of the story, the moral of which is that "we made this" and so too will we overcome it.

Viewed through this rose-coloured filter, the image of the black hole might be positioned as support for this narrative, one wherein humanity is not only capable of imaging the Earth from a distance, but of controlling and transforming its geology, climate, and future trajectories. However, if I have learned anything from black holes so far, it is that this is but one way of approaching its apparent horizons. As Reed (2019) might remind us, "the meaning and comprehensive significance of scientific development is not as matter-of-fact as the concrete discovery itself" (p. 29). There are alternative narrations emanating from this stellar object, albeit ones that have been necessarily obfuscated so as to affirm and reproduce dominant cosmological orders. After all, what was produced by the EHT does not technically show visual evidence of 
a black hole, for as we saw (or perhaps didn't see), black holes are, by definition, completely dark incredibly dense objects from which even light cannot escape. Instead, the image shows a shadow, a boundary of perceptibility that manifests in darkness, forever exceeding human representational schema. This sense of darkness has been expressed through the designation of the black hole itself, which was bestowed with the name Pōwehi, a Hawaiian word that comes from the Kumulipo, an eighteenth-century creation chant, and means "the adorned fathomless dark creation" or "embellished dark source of unending creation" (Mele, 2019). In contrast to images of human curiosity and wonder, of enlightenment and insight, in the narrative of Pōwehi, the black hole image instead signals a horizon-a limit case-for human sense-making apparatuses.

This limit is evidenced through the creation of the EHT image itself, which not only required an international team of human scientists, but, perhaps more importantly, necessitated a complex meshwork of inhuman and nonhuman sense-making assemblages. In order to capture the image, the EHT project needed to create an incredibly large telescope capable of reaching galaxy Messier 87, which involved the help of a powerful machine-learning algorithm that could stitch together data collected from telescopes scattered around the globe while also discerning "good" images from "noise" and calculating for hidden delays in astronomical signal processing. While the working parts of this inhuman/non-human assemblage are too extensive to detail here, a starting list includes: 8 radio telescopes, atomic clocks (a.k.a. hydrogen masers), thousands of terabytes of data, highly specialized supercomputers, three different algorithmic imaging methods, and 13 stakeholder institutions (plus over 60 affiliated institutions). And, if we were to unravel each of these elements, the list would, of course, grow exponentially, revealing a complex network of partial objects and machinic flows that challenge the very notion of creating a bulleted list.

By interpolating the black hole image through its technical apparatus, the narrative contingencies that support the cosmological presumption that this technological feat reflects an all-too-human ingenuity is made vulnerable. Taking this into account, the 2019 image of the black hole may, once again, follow in the footsteps of Earthrise as an iconic environmental image-a representation of these anthropocenic times-albeit one that pushes back against (Good) Anthropocene impulses and desires. In contradistinction to fantasies of anthropic omnipotence and planetary control, the black hole image, in both its form and content, instead affirms a cosmological milieu characterized by rhythms and patternings of inhuman and non-human cosmic forces far beyond our perception, let alone control. In this narrative, the human species is resituated as but a partial component in a dynamic network of connections that resist God-like, totalizing views and tidy causal determinations. Resituated in this way, the 2019 black hole image might indeed be put forth as an important "message to humanity," alerting us, for instance, to the ways in which "[ $t]$ he 'human' is not, except as an effect of complex, shifting, becoming relations among a multiplicity of actants" (Weaver \& Snaza, 2016, p. 1063). 
From this resituated position, the pedagogical question is not just about how to better explain or theorize or understand this knowledge, but how to exist in this knowledge, that is, how to navigate the alien milieus that are opened up when the situatedness of thought exceeds the commonsense categories and delineations that have come to undergird a given cosmological milieu. As Reed writes, "situated thought may always stem from a partial position embedded within a particular (cosmological) milieu, but neither that position nor that milieu is fixed absolutely; it is subject to the forces of thought's speculative mobility to permeate the given and render its subtending mythical grounds temporary" (p. 30). In the case of the black hole, the question is thus how to sustain encounters with this force of thought and the risks and uncertainties that come with it.

\section{Alien Territories: Thwarting Laplacean Dreams, Resituating Sustainability}

It is here where the question of (science) education returns to the forefront. Of the narrative contingencies traced above, it might be wagered, as I do here, that dominant educational discourses today conform to (Good) Anthropocene vibes, in turn dejecting and obscuring some of the more unfathomable aspects that might otherwise be raised by the Anthropocene designation. While ecological catastrophes gather force and speed around the globe, alongside a range of distressing social, political, and psychological crises, education (and its reasons) has yet to fully confront the bleak realization that the planet is undergoing uncertain and catastrophic transformations. Indeed, one of the main, if obscured, stakes raised by the current moment of ecological degradation concerns the very existence of humans on planet Earth, or to put it bluntly, "the emerging path that we are collectively clearing that leads towards the end of human earthly habitation" (Heimans, 2018, p. 6). As Jason Wallin (2017) notes, the significance of educational research today should therefore be predicated on its ability to engage with the ecological, economic, and political challenges of the Anthropocene. As he writes: "to deny that education must be fundamentally rethought in relation to such ecological complexity marks a failure to engage not only the challenges to human and non-human life intimate to the [A]nthropocene, but a reluctance to forge a speculative encounter with the quite real potential of human extinction" (p. 1100).

This non-confrontation with today's planetary realities is not only evidenced by education's more conservative approaches, but is also made manifest by well-intentioned "progressive" approaches, many of which take cues from (Good) Anthropocene narratives and impulses, perhaps unknowingly. For instance, education is often nominated as an important player in "sustainable development" and, as such, it is positioned as one of the most "powerful tools for transformation, in order to make the Anthropocene long-lasting, equitable, and worth living" (Leinfelder, 2013, p. 10). Here, education is oriented towards "envisioning a sustainable human presence on Earth in which humans 
would no longer be 'invaders' but rather participants in shaping the natural environment" (Leinfelder, 2013, p. 9). The cosmological presumptions of this orientation are in line with those of broader (Good) Anthropocene narratives wherein humans are positioned as geological agents that must "take this agency upon themselves and direct it better than it has thus far been directed" (Snaza, 2018, p. 339). Within this narrative, the Anthropocene is not seen as a "'crisis to end all crises,' the catalyst needed to provoke real change" in educational domains, as Gilbert $(2016$, p. 188) puts it, but is instead positioned as an opportunity to reform and responsibilize education towards more sustainable practices.

As such, this narrative not only downplays and denies the current reality of anthropogenic climate change and its coming (or in many cases, current) annihilations, but provides a breeding ground for a "new" education to emerge, an education after education, wherein our current planetary predicament is simply an aberration in need of rehabilitation and re-engineering. Within this redemptive narrative, it is simply assumed that education will forever be founded on the project of (human) sustainability and an ultimately positive, or "Good," future for "us." In turn, potentials for conceiving educational futurity from the unfathomable perspective of, for instance, human extinction and ecocatastrophic abolition, are disappeared and occluded in the name of the (Good) Anthropocene's imperative to sustain current cosmological orders, no matter the cost. Put bluntly, a confrontation with the pressing issues of insufficiency, finitude, diminishment, divestment, and extinction that might otherwise re-orient educational futurity in these anthropocenic times is disappeared and replaced with a vision of times-to-come that are always-already given in adequation to a present of which the future is a mere perpetuation.

Caught amidst this perpetual present, attempts to rethink (science) education must therefore not only interrogate current educational situations, but must actively experiment with speculative pedagogical trajectories that involve processes of alienation that are able to "denaturalize the givenness of a certain worldpicture, our position, and the understanding of our agencies within it" (Reed, 2019, p. 28). As Reed (2019) asserts, knowing about something like anthropogenic climate change is very different than existing in that knowledge, raising the important, if uncomfortable, point that the necessary illusions and obfuscations through which the (Good) Anthropocene is realized do not suddenly dissolve and transform because we are shown, scientifically or otherwise, differently. With this in mind, the task of rethinking education is not just about knowing more or even knowing differently, but instead about creating speculative methods and hypothetical probes that might catalyze processes of alienation from one world to a desired otherworld. It is here where the image of Pōwehi-that image of "adorned fathomless dark creation"-returns to the frame.

In addition to providing an index of anthropic limits and the power of inhuman and non-human planetary sensing, the black hole image produced 
by EHT offers one site where practices of speculative alienation might be exercised so as to interrupt and mutate some of the inheritances that have come to define and delimit possibilities for rethinking (science) education. As just one example of such inheritances, and to bring us back into the world of black hole physics once again, we might look, for instance, to something like causal determinism. Causal determinism, also known as "Laplace's demon," is the theory that all physical events in the universe are determined completely by previously existing causes, or the idea that every event is necessitated by antecedent events and conditions alongside the "the laws of nature" (Weaver \& Snaza, 2016 , p. 1055). The pedagogical example used to explain this goes something like this: if some omnipotent being (the demon) could account for the precise location and momentum of all matter in the universe, both the past and future state of this mattering could be predetermined in a causal manner through the formulas and calculations provided by the "laws" of physics. Within this narrative of the cosmos, the future is not inherently unknown, but rather, its unknowability is the result of inadequate information. As such, causal determinism hypothesizes that if we could gather enough data alongside the ability to sort through and manage that information, we would be able to account for all of time. Thinking back to the distinction between event and apparent horizons, it is partly through the narrative contingencies of casual determinism that the very existence of absolute horizons, wherein the future is defined teleologically, is supported.

Causal determinism undergirds much scientific theory and practice, but also extends and intersects with a larger tapestry of philosophical, social, economic, political, and cultural significations. Alex Garland's (2020) timely sciencefiction miniseries Devs provides one example of such intersections, in this case presenting a speculative account of what might happen if Laplace's demon were to be actualized by harnessing the power of big data and quantum computing. (Spoiler alert, it doesn't end well.) Theories of causal determinism also have educational significations and implications. As educational theorists John Weaver and Nathan Snaza (2016) assert, for instance, the "Laplacean dream"- one wherein reality can be ordered around the "the certainty of facts, the predictability of the future, the stability of isolated phenomenon, the universalization of mathematical thinking [and] the necessity of hypothetical/deductive thinking" (p. 1055) - has come to undergird the very practice of educational research. Further, it is, in part, the "Laplacean dream" that foregrounds postures of anthropic omnipotence and thus the possibility of seeing the Earth from a distance, seeing it as a known "object" over which an all-knowing transcendent "subject" (called humanity) is able to capture, manipulate, and control planetary realities. This deterministic dream not only prioritizes consistency over contingency, standardized and standardizing techniques, and a posture of anthropocentrism that erases phenomena that cannot be accounted for in deterministic ways, but also positions the future as something that can be predicted and controlled, so long as we have 
adequate information and the correct calculations. Within this narrative, questions of sustainability are driven by the cosmological presumption that "we" humans will be able to overcome the unsustainability of the present world order through careful accounting, strategic risk-management, and mitigation strategies so as to sustain present political, social, and ecological orders.

The black hole image, however, provides an unsettling reminder of how the conceptual categories to which we have become accustomed-be it "Laplacean dreams," illusions of well-intentioned geologic agency or fantasies of a redeemed and redeeming educational future-are narratively contingent and thus vulnerable to alternative speculations. By thwarting the "Laplacean dream" of isolated phenomena, objective stability, and the universalization of mathematical calculation, for instance, the black hole image provides an encounter with a potential limit case for scientific intelligibility, rendering epistemology itself mute and in need of new means of hypothetical expression. Put another way, the black hole image provides "proof," albeit paradoxically, of a physical phenomenon that puts at risk what, and on what basis, we can claim to "know" things in the first place. At the same time that the image provides "visual evidence" of a cosmic event that affirms fundamental cosmological presumptions about the universe, it simultaneously provides evidence of an actual limit case for testing such hypotheses. As such, no matter how complex the technological mediations and interpretations, no matter how nuanced the theorizations of, for instance, quantum states and apparent horizons might be, it cannot be determined once and for all whether black holes do, in fact, conform to the "laws" of science.

After all, and to paraphrase Steven Hawking (2008), if an object were to enter the event horizon of a black hole, we wouldn't be able to predict the future of that object because there is no telling what occurs at the event horizon. As Hawking (2008) quips: "[i]t could emit a working television set, or a leather bound volume of the complete works of Shakespeare, though the chance of such exotic emissions is very low. It is much more likely to be thermal radiation, like the glow from red hot metal" (para. 14). What is significant here is that if causal determinism, and thus the very "laws" of science, do not hold in this instance then there is always the possibility they might not hold in other situations. As Hawking (2008) puts it:

[t]here could be virtual black holes that appear as fluctuations out of the vacuum, absorb one set of particles, emit another, and disappear into the vacuum again. Even worse, if determinism breaks down, we can't be sure of our past history either. The history books and our memories could just be illusions. It is the past that tells us who we are. Without it, we lose our identity. (para. 14)

With Hawking's words in mind, the black hole image not only provides "evidence" of a limit case for scientific intelligibility, but, importantly for this tracing, conjures a weird encounter with an unthinkable thought-with that 
which we cannot even begin to think-an encounter with an unfathomable event wherein the cosmos itself ties a knot that cannot be untied. What this encounter reveals is not only the limits of human exploration and intelligibility, but also how the commonsense categories, delineations, and correlations through which we make sense of the world on a more daily basis are perhaps much, much stranger than we like to think. Or as theoretical physicist often attributed to popularizing the term "black hole," John Wheeler (2000), puts it, "[the black hole] teaches us that space can be crumpled like a piece of paper into an infinitesimal dot, that time can be extinguished like a blown-out flame, and that the laws of physics that we regard as 'sacred,' as immutable, are anything but" (p. 298). In short, in this weird narration, the black hole image provides an encounter with the perplexing thought that "[n]othing can be said, here and now, to be impossible or to be closed down or determined once and for all $[\ldots]$ the only impossibility is the determination in advance that certain events would be impossible" (Colebrook, 2016, p. 103).

Returning to the question of rethinking (science) education in/and the Anthropocene, the pedagogical task is how to exist in such a thought, that is, how to sustain an encounter with the alien milieus that open up, "milieus that are both bristling with the possibilities and fraught with the risks and uncertainties that come with it" (Reed, 2019, p. 30). For me, this is a very different notion of sustainability than that which is most often proffered by (Good) Anthropocene narratives and their advocates. In this narrative of sustainability the goal is not to maintain and perpetuate current cosmological orders, but instead, to sustain the active practice of confronting and re-working the pain and pleasure, the urgency and exhaustion, the deep discomfort and existential uncertainty that comes with existing in knowing, or rather, existing in not knowing. With this resituated notion of sustainability in mind, and as a way to conclude, the black hole image offers a site wherein the promise of a "new," more sustainable (science) education after education, is dislodged and made vulnerable to revision and, perhaps, rethinking. As Reed (2019) concludes in her own investigation of enabling resituation, while it is "indispensable to map the diagnostic terrain we find ourselves in, including the cosmological predispositions that have legitimized these processes, $[\ldots]$ it is equally crucial to speculate on the locations, means and alternative narrations to make the current, entirely destructive path we are on an object of history" (p. 34). Taking cues from Reed one last time, the 2019 black hole image is not offered up here as a new framework or metaphor for (science) education, but instead provides just one experimental site (we might also look to reality $\mathrm{TV}$, financial derivatives, or glacial melt) for navigating alien territories and developing sustainable practices capable of speculating on education and its future(s) otherwise. 


\section{REFERENCES}

Anders, W. (Photographer). (1968, December 24). Earthrise. http://www.hq.nasa. gov/office/pao/History/alsj/a410/AS8-14-2383HR.jpg.

Anders, B. (2018). 50 years after 'Earthrise,' a Christmas Eve message from its photographer. https://www.space.com/42848-earthrise-photo-apollo-8-legacy-billanders.html.

Bonneuil, C., \& Fressoz, J. (2016). The shock of the Anthropocene: The earth, history, and $u s$. Verso.

Chappell, B. (2019). Earth sees first image of a black hole. NPR. https://www.npr. org/2019/04/10/711723383/watch-earth-gets-its-first-look-at-a-black-hole.

Colebrook, C. (2016). What is the anthropo-political? In T. Cohen, C. Colebrook, \& J. H. Miller (Eds.), Twilight of the Anthropocene idols (pp. 81-125). Open Humanities Press.

Coulter, D. (2009). Exploring the moon, discovering Earth. NASA Science. https:// science.nasa.gov/science-news/science-at-nasa/2009/17jul_discoveringearth.

Cureil, E. (2019). The many definitions of a black hole. Nature Astronomy, 3(1), 27-34.

Drake, N. (2019). First-ever picture of a black hole unveiled. National Geographic. https://www.nationalgeographic.com/science/2019/04/first-pictureblack-hole-revealed-m87-event-horizon-telescope-astrophysics/.

EHT Collaboration. (2019, April 10). First image of a black hole. https://www.eso. org/public/images/esol907a/.

Ellis, E. (2009). Stop trying to save the planet. Wired. https://www.wired.com/ $2009 / 05 /$ ftf-ellis- $1 /$.

Ellis, E. (2011). Forget mother nature: This is a world of our making. New Scientist. https://www.newscientist.com/article/mg21028165-700-forget-mothernature-this-is-a-world-of-our-making/.

Garland, A. (Director). (2020). Devs [TV miniseries]. DNA TV.

Gilbert, J. (2016). Transforming science education for the Anthropocene-Is it possible? Research in Science Education, 46(2), 187-201.

Haraway, D. (1988). Situated knowledges: The science question in feminism and the privilege of partial perspective. Feminist Studies, 14(3), 575-599.

Hawking, S. (2008). Into a black hole. http://www.hawking.org.uk/into-a-black-hole. html.

Hawking, S. (2014). Information preservation and weather forecasting for black holes. arXiv:1401.576lvl.

Heimans, S. (2018). The world is gone, I must carry you: A provocation for doing post-critical educational research with the Anthropocene. In V. C. Reyes (Ed.), Educational research in the age of Anthropocene. Information Science Reference.

Leinfelder, R. (2013). Assuming responsibility for the Anthropocene: Challenges and opportunities in education. In H. Trischler (Ed.), Anthropocene: Exploring the future of the age of humans (pp. 9-28). RCC Perspectives.

Lewis, S. L., \& Maslin, M. A. (2015). Defining the Anthropocene. Nature, 519(7542), 171-180.

Mele, C. (2019). That first black hole seen in an image is now called Pōwehi, at least in Hawaii. The New York Times. https://www.nytimes.com/2019/04/13/science/ powehi-black-hole.html. 
Moran, J. (2018). Earthrise: The story behind our planet's most famous photo. The Guardian. https://www.theguardian.com/artanddesign/2018/dec/22/beh old-blue-plant-photograph-earthrise.

O'Hagan, E. M. (2019). Why the black hole is a ray of light in these dark times. The Guardian. https://www.theguardian.com/commentisfree/2019/apr/ 11/black-hole-science-humanity.

Reed, P. (2019). Platform cosmologies: Enabling resituation. Angelaki: Journal of Theoretical Humanities, 24(1), 27-36.

Reuell, P. (2019). A black hole, revealed. The Harvard Gazette. https://news.har vard.edu/gazette/story/2019/04/harvard-scientists-shed-light-on-importance-ofblack-hole-image/

Snaza, N. (2018). The earth is not "ours" to save. In J. Jagodzinski (Ed.), Interrogating the Anthropocene: Ecology, aesthetics, pedagogy, and the future in question. Palgrave Macmillan.

Wallin, J. J. (2017). Pedagogy at the brink of the post-Anthropocene. Educational Philosophy \& Theory, 49(11), 1099-1111.

Weaver, J. A., \& Snaza, N. (2016). Against methodocentrism in educational research. Educational Philosophy and Theory, 49(11), 1055-1065.

Wheeler, J. A., \& Ford, K. W. (2000). Geons, black holes, and quantum foam: A life in physics. Norton.

Williams, D. R. (n.d.). The Apollo 8 Christmas Eve broadcast. https://nssdc.gsfc. nasa.gov/planetary/lunar/apollo8_xmas.html.

Zylinska, J. (2018). The end of man: A feminist counterapocalypse. University of Minnesota Press.

Open Access This chapter is licensed under the terms of the Creative Commons Attribution 4.0 International License (http://creativecommons.org/licenses/by/4.0/), which permits use, sharing, adaptation, distribution and reproduction in any medium or format, as long as you give appropriate credit to the original author(s) and the source, provide a link to the Creative Commons license and indicate if changes were made.

The images or other third party material in this chapter are included in the chapter's Creative Commons license, unless indicated otherwise in a credit line to the material. If material is not included in the chapter's Creative Commons license and your intended use is not permitted by statutory regulation or exceeds the permitted use, you will need to obtain permission directly from the copyright holder.

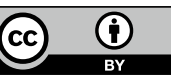

